\title{
Effect of biological sex differences on the perception of acute pain stimulation in the dental setting
}

\author{
Ilana Eli DMD, Yoram Bar-Tal PhD, Zvi Fuss DMD, Ethan Korff DMD
}

I Eli, Y Bar-Tal, Z Fuss, E Korff.

Effect of biological sex differences on the perception of acute pain stimulation in the dental setting.

Pain Res Manage 1996;1(4):201-206.

BACKGROUND: Pain is a subjective sensory and emotional experience that is influenced by variables such as stress, anxiety and sex.

OBJECTIVE: To investigate the interrelationship among sex, state and dental anxiety, and the patient's reaction to diagnostic tooth pulp stimulation.

SUBJECTS AND DESIGN: The study was conducted on 64 dental patients (age 18 to 78 years, $50 \%$ were female). All subjects were evaluated twice. At time 1, subjects were requested to fill out questionnaires concerning their state and dental anxiety, and participants underwent diagnostic tooth pulp stimulation by an electric pulp tester. Four variables of the experience were recorded: sensation threshold, pain threshold, pain tolerance and the subjective evaluation of the painful experience on a visual analogue scale (VAS). At time 2, subjects were requested to record their memory of the previous experience on a VAS, and the whole procedure was repeated including record of state and dental anxiety, sensation and pain thresholds, pain tolerance and its subjective evaluation on a VAS.

RESULTS: No direct correlations were found between sex and any other variable. However, there were significant differences in the relationship among the different pain and anxiety measures between both sexes.

CONCLUSIONS: A man's reaction to acute pain stimulation may be more affected by psychological factors than a woman's.

Key Words: Acute pain, Anxiety, Dental setting, Sex

\section{Effet des différences biologiques liées au sexe sur la perception d'une stimulation douloureuse aiguë dans le contexte dentaire}

HISTORIQUE : La douleur est une expérience sensorielle et émotionnelle subjective influencée par des variables comme le stress, l'anxiété et le sexe.

OBJECTIF : Investiguer les relations entre sexe, état et anxiété dentaire, et la réaction du patient à la stimulation diagnostique de la pulpe dentaire.

SUJETS ET MODÈLE : L'étude a été menée sur 64 patients dentaires (âgés de 18 à 78 ans, $50 \%$ de sexe féminin). Tous les sujets ont subi deux évaluations. Au temps 1 , on a demandé aux sujets de remplir des questionnaires concernant leur état et leur anxiété dentaire, et les participants ont subi une stimulation diagnostique de la pulpe dentaire au moyen d'un testeur de pulpe électrique. On a enregistré 4 variables de l'expérience : le seuil de sensation, le seuil de la douleur, la tolérance à la douleur et l'évaluation subjective de l'expérience douloureuse sur une échelle visuelle analogique (EVA). Au temps 2, on a demandé aux sujets de qualifier le souvenir de l'expérience antérieure sur une EVA, et on a répété l'ensemble de la procédure en incluant les données consignées sur l'état et l'anxiété dentaire, le seuil de la sensation et de la douleur, la tolérance à la douleur et son évaluation subjective sur une EVA.

RÉSULTATS : Aucune corrélation directe n'a pu être démontrée entre le sexe ou toute autre variable. Cependant, on a noté des différences significatives entre les deux sexes dans la relation entre les différentes mesures de la douleur et de l'anxiété.

CONCLUSIONS : Chez l'homme, la réaction à une stimulation douloureuse aiguë pourrait être plus influencée par des facteurs psychologiques que chez la femme.

Department of Occlusion and Behavioral Sciences, and Department of Endodontology, The Maurice and Gabriela Goldschleger School of Dental Medicine; and Department of Nursing, School of Health Professionals, The Sackler Faculty of Medicine, Tel Aviv University, Tel Aviv, Israel

Correspondence: Dr I Eli, The Maurice and Gabriela Goldschleger School of Dental Medicine, Tel Aviv University, Tel Aviv, Israel.

Telephone 972-3-6409306, fax 972-3-6409250, e-mail elilana@ccsg.tau.ac.il

Accepted for publication October 21, 1996 
$\mathrm{P}$ ain is a sensory as well as an emotional experience frequently associated with the dental setting. Fear of pain and mutilation (eg, tissue damage) has been found to be closely related to dental fear (1). Although many dentists deny that their patients experience pain during treatment (2), up to $77 \%$ of patients report some degree of pain during their visits (3).

Stress and anxiety are common emotional concomitants of acute pain (4). Generally, when anxiety exists the perception of noxious events as painful are increased (5-8). In dentistry, the amount of pain expected and experienced by patients is directly related to their anxiety (9-13). Highly fearful dental patients were similar to nonfearful patients with regards to their pain threshold (PTh) or pain tolerance (PT) of nondental stimuli (electric stimulation of the forearm). The former, however, rated dental stimuli (tooth pulp stimulation) as more painful than did nonfearful patients $(10,14)$.

One's expectations of a given situation can influence the final interpretation of the stimulus. An ambiguous sensation can be perceived as either pleasurable or painful based on the expectancy or schematic representation of the stimulus (15). Studies of tooth pulp stimulation, delivered in a psychological laboratory or in a clinical dental setting, produce evidence that responses to pain change according to the situation in which the pain is experienced (16). Subjects showed a substantial decrease in their sensation threshold (STh), PTh and PT when tests were performed in the dental clinic, indicating that the anticipation of threat in such a setting and the associated anxiety are cognitive mediators of pain behaviour.

The cognitive aspects of the pain experience (beliefs, expectations) are affected by the extent to which the individual recalls a former painful experience. Although research on the memory of pain (MEP) is a relatively new area, an increasing amount of information suggests that the accuracy of such memory depends on a number of variables. A patient's memory of acute pain during dental treatment is often affected by the level of dental anxiety. Kent (17) found that incidents recalled by patients with high anxiety were significantly more unpleasant than those with moderate and low anxiety, indicating that anxiety affects the description of previous experiences. In another study, anxious patients reported more pain three months after a dental appointment than immediately after treatment. The level of pain remembered by the patients was more closely associated with their expectations of pain than with their real previous experience (13).

In the scientific community, the issue of sex differences and pain has gained increasing attention. Ruda (18) summarized that most of the sex issues relating to pain can be separated into those based on anatomical differences and those concerning pain conditions that are more prevalent in either of the sexes. Nevertheless, other issues, such as differences in accepted behaviours between men and women, as well as the effect of attitudes, preconceptions and biases, should be further explored (18).

The current literature on sex differences in response to pain stimuli is controversial. While Bush et al (19) reported that they found only a few differences based on ratings of chronic and experimental pain and pain-related illness behaviour, Lautenbacher and Rollman (20) showed significant differences between sexes in electrical detection, PT and tolerance thresholds.

In dentistry (and in medicine), a patient's report regarding pain serves as an important diagnostic tool. The dentist (or physician) is able to locate the possible pathology and to reach a conclusion concerning diagnosis and treatment. An example is the use of electric tooth stimulation as a main diagnostic test for tooth pulp vitality (21). However, the high incidence of stress, fear and anxiety among dental patients (22-24), the influence of anxiety on the pain experience and possible sex differences call for a reserved relation to the individual pain report $(22,25)$.

The main objectives of the present exploratory study were to evaluate the effect of anxiety and sex differences on patients' pain perception during diagnostic tooth pulp stimulation.

\section{Subject evaluation}

\section{SUBJECTS AND METHODS}

A large group of patients who were under dental treatment at the School of Dental Medicine, Tel Aviv University, Tel Aviv, Israel were initially screened to choose those clinically acceptable to participate in the study. Clinically, the presence of two intact, maxillary central incisal teeth, with no signs of caries, no former restorations and no signs of evident abrasion or trauma, was required. Periapical radiographs were used to ensure normal pulp anatomy. The final study was conducted on 64 subjects age 18 to 78 years (mean 37.5 ); $50 \%$ were female. Subjects were told that the tooth pulp stimulation they were about to experience was part of a routine dental examination and were requested to report their evaluation of the experience as part of a general clinical study in the field of clinical diagnosis.

\section{Evaluation of anxiety level (time 1)}

To assess the level of anxiety, all subjects were requested to complete the following questionnaires.

The State Anxiety Inventory: The State Anxiety Inventory scale contains 20 statements, such as "I feel tense", with a four-point response format that ranges from 1 (not at all) to 4 (very much so) (26). The score was coded as state anxiety (SA1). The questionnaire showed an acceptable rate of reliability in the present study (Cronbach's $\alpha=0.83$ ).

Dental Anxiety Scale: The Dental Anxiety Scale (DAS) was used as a specific measure of dental fear (27). Using a five-point scale, subjects rated the amount of fear that they would feel if they had to go to the dentist, wait in the dentist's office, sit in the dentist's chair and wait in the dentist's chair to have their teeth cleaned (the higher the score, the higher the dental anxiety). The score was coded as dental anxiety (DAS1). The DAS has a high predictive validity rate (28) and has been used extensively in various dental settings (2939). The DAS showed an acceptable reliability rate in the present study (Cronbach's $\alpha=0.92$ ).

\section{Tooth pulp stimulation (time 1)}

During the initial encounter, electric tooth pulp stimulation was performed on the maxillary right incisor of each subject with an electric pulp tester (EPT) (Vitality Scanner, Analytic Technology, Washington) by a male experimenter. The EPT was placed on the incisal third of the tooth crown and stimulation intensity automatically increased with minimal pace of change (grade 1). Subjects were asked to indicate the moment an initial sensation was felt (STh at time 1 [STh1]), the moment initial pain was experienced (PTh at time 1 [PTh1]) and the moment the experiment should cease because of pain (PT at time 1 [PT1]). 


\begin{tabular}{|c|c|c|}
\hline Variable & Time $1($ mean \pm SD $)$ & Time $2($ mean $\pm S D)$ \\
\hline DAS & $8.38 \pm 3.02$ & $8.27 \pm 3.00$ \\
\hline SA & $1.41 \pm 0.51$ & $1.42 \pm 0.42$ \\
\hline STh & $10.23 \pm 9.57$ & $8.47 \pm 8.49$ \\
\hline PTh & $17.81 \pm 10.86$ & $15.83 \pm 10.08$ \\
\hline PT & $25.95 \pm 13.61$ & $27.36 \pm 15.47$ \\
\hline PVAS & $57.97 \pm 17.38$ & $58.47 \pm 17.20$ \\
\hline MEP & - & $59.45 \pm 15.25$ \\
\hline
\end{tabular}

DAS Dental anxiety; MEP Memory of the pain experience on a visual analogue scale (VAS); PT Pain tolerance; PTh Pain threshold; PVAS Evaluation of pain on a VAS; SA State anxiety; STh Sensation threshold

TABLE 2

Correlation (Pearson correlation coefficients) matrix among study variables at first measurement (time 1)

\begin{tabular}{lcccccc}
\hline Variable & DAS1 & SA1 & STh1 & PTh1 & PT1 & PVAS1 \\
\hline SA1 & 0.05 & & & & & \\
STh1 & -0.22 & -0.05 & & & & \\
PTh1 & $-0.30^{* *}$ & -0.02 & $0.89 *$ & & & \\
PT1 & 0.23 & 0.09 & $0.70^{*}$ & $0.77^{*}$ & & \\
PVAS1 & 0.06 & 0.25 & -0.02 & 0.01 & -0.03 & \\
MEP & 0.13 & 0.17 & -0.05 & -0.09 & -0.03 & $0.70^{*}$ \\
\hline
\end{tabular}

*P<0.01: **P<0.05. DAS1 Dental anxiety at time 1: MEP Memory of the pain experience on a visual analogue scale (VAS) (recorded at time 2); PT1 Pain tolerance at time 1; PTh1 Pain threshold at time 1; PVAS1 Evaluation of pain on a VAS at time 1; SA1 State anxiety at time 1; STh1 Sensation threshold at time 1

Immediately after stimulation, subjects were asked to report the maximal degree of pain experienced during the experiment on a visual analogue scale (VAS) ranging from 0 to 10 (PVAS1).

Record of MEP and repeated tooth pulp stimulation (time 2) All 64 subjects were re-examined after eight to 10 weeks. Subjects were asked to complete the State Anxiety Inventory and the DAS again. The scores obtained were coded as SA2 and DAS2. Subjects were then asked about their memories of the maximal pain experienced during the EPT stimulations performed previously (on a VAS). Scores were coded as MEP. EPT stimulations were repeated and recorded as previously described, and coded as STh2, PTh2, PT2 and PVAS2 respectively.

\section{RESULTS}

Mean values and SDs of study variables are presented in Table 1. Correlation matrices among the study variables are presented in Tables 2 to 4 .

Two major patterns emerge from the tables. First, significant correlations were found between the subject's dental anxiety and PTh, but not with any other pain variables (STh, PT). No significant correlations were found between a subject's dental anxiety and the subjective evaluations of the painful experience on a VAS (PVAS and MEP).
TABLE 3

Correlation (Pearson correlation coefficients) matrix among study variables at second measurement (time 2)

\begin{tabular}{lcccccc}
\hline Variable & DAS2 & SA2 & STh2 & PTh2 & PT2 & PVAS2 \\
\hline SA2 & 0.05 & & & & & \\
STh2 & -0.23 & -0.07 & & & & \\
PTh2 & $-0.33^{*}$ & -0.16 & $0.88^{*}$ & & & \\
PT2 & -0.16 & -0.00 & $0.49 *$ & $0.61^{*}$ & & \\
PVAS2 & 0.05 & 0.21 & -0.05 & -0.04 & -0.02 & \\
MEP & 0.13 & 0.17 & -0.20 & -0.22 & -0.04 & $0.76^{*}$
\end{tabular}

${ }^{*} P<0.01$. DAS2 Dental anxiety at time 2; MEP Memory of the pain experience from time 1 on a visual analogue scale (VAS) (recorded at time 2); PT2 Pain tolerance at time 2; PTh2 Pain threshold at time 2; PVAS2 Evaluation of pain on a VAS at time 2; SA2 State anxiety at time 2; STh2 Sensation threshold at time 2

TABLE 4

Correlations (Pearson correlation coefficients) among pain variables at the two measurement points (times 1 and 2)

\begin{tabular}{lllll}
\hline Variable & STh2 & PTh2 & PT2 & PVAS2 \\
\cline { 1 - 3 } STh1 & $0.82^{*}$ & $0.82^{*}$ & $0.52^{*}$ & 0.02 \\
PTh1 & $0.77^{*}$ & $0.86^{*}$ & $0.58^{*}$ & 0.04 \\
PT1 & $0.63^{*}$ & $0.73^{*}$ & $0.81^{*}$ & 0.05 \\
PVAS1 & -0.04 & -0.07 & -0.07 & $0.74^{*}$
\end{tabular}

${ }^{*} P<0.01$. PT1 Pain tolerance at time 1; PT2 Pain tolerance at time 2; PTh1 Pain threshold at time 1; PTh2 Pain threshold at time 2; PVAS1 Evaluation of pain on a visual analogue scale (VAS) at time 1; PVAS2 Evaluation of pain on a VAS at time 2; STh1 Sensation threshold at time 1; STh2 Sensation threshold at time 2

TABLE 5

Variables of pain and anxiety as a function of sex and time of measurement

\begin{tabular}{|c|c|c|}
\hline Variable & Male & Female \\
\hline \multicolumn{3}{|l|}{ Time 1} \\
\hline DAS1 & $8.50 \pm 3.09$ & $8.25 \pm 2.99$ \\
\hline SA1 & $1.53 \pm 0.61$ & $1.35 \pm 0.36$ \\
\hline STh1 & $9.84 \pm 10.31$ & $10.63 \pm 8.92$ \\
\hline PTh1 & $17.88 \pm 12.33$ & $17.75 \pm 9.36$ \\
\hline PT1 & $27.59 \pm 16.57$ & $24.31 \pm 9.79$ \\
\hline PVAS1 & $58.44 \pm 16.73$ & $57.50 \pm 18.27$ \\
\hline \multicolumn{3}{|l|}{ Time 2} \\
\hline MEP & $59.53 \pm 14.83$ & $59.38 \pm 15.90$ \\
\hline DAS2 & $8.22 \pm 3.08$ & $8.31 \pm 2.98$ \\
\hline SA2 & $1.43 \pm 0.42$ & $1.39 \pm 0.41$ \\
\hline STh2 & $7.78 \pm 8.90$ & $9.16 \pm 8.14$ \\
\hline PTh2 & $15.06 \pm 10.97$ & $16.59 \pm 9.21$ \\
\hline PT2 & $30.28 \pm 19.07$ & $24.44 \pm 10.26$ \\
\hline PVAS2 & $60.94 \pm 13.99$ & $56.00 \pm 19.82$ \\
\hline \multicolumn{3}{|c|}{$\begin{array}{l}\text { DAS1 Dental anxiety at time 1; DAS2 Dental anxiety at time 2; } \\
\text { MEP Memory of the pain experience on a visual analogue scale (VAS); } \\
\text { PT1 Pain tolerance at time 1; PT2 Pain tolerance at time 2; PTh1 Pain } \\
\text { threshold at time 1; PTh2 Pain threshold at time 2; PVAS1 Evaluation } \\
\text { of pain on a VAS at time 1; PVAS2 Evaluation of pain on a VAS at } \\
\text { time 2; SA1 State anxiety at time 1; SA2 State anxiety at time 2; } \\
\text { STh1 Sensation threshold at time 1; STh2 Sensation threshold at } \\
\text { time } 2\end{array}$} \\
\hline
\end{tabular}


Second, among the three pain threshold measures (STh, PTh and PT), as well as between the two evaluative pain measures (PVAS and MEP), high correlations were observed. There were, however, no significant correlations between the pain threshold measures and the evaluative pain measures. Both patterns were similar at both test times.

A series of $t$ tests to examine the effect of sex and the study variables revealed no significant effects (mean scores are listed in Table 5).

To examine the possibility that sex differences affect the relationship among the pain measures, two ANOVAs were performed. The first analysis examined whether a different pattern of the evaluative pain measures (PVAS1, MEP and PVAS2) exists in men and women ( $2 \times 3$ within-between ANOVA). This analysis did not yield any significant results. The second analysis examined whether there was a different pattern of the PTh measures in the two measurement points. A $2 \times 2 \times 3$ within-between ANOVA was performed, in which men versus women served as a between factor, and the three pain measures (STh, PTh and PT) and the two measurement points (time 1 and 2) served as within factors.

The results of the analysis yielded three significant effects. First, significant differences were found among the three pain threshold measures (STh, PTh, PT) in which the STh (mean=9.35) was lower than the PTh $($ mean=16.82), and the latter was lower than PT $($ mean $=26.66)\left(\mathrm{F}_{(2,124)}=49.03, \mathrm{P}<0.01\right)$. Next, two-way interaction of type of pain measure $x$ two measurement points $\left(F_{(2,124)}=130.55\right.$, $\mathrm{P}<0.01)$ were found to be significant. Since this interaction was qualified by a higher order interaction, only the latter will be discussed. Third, three-way interaction of type of pain measure $x$ two measurement points $x \operatorname{sex}\left(F_{(2,124)}=4.78, P=0.01\right)$ were found to be significant.

Table 5 presents the cell means of the variables. It can be observed that, the three pain threshold measures differed across measurement points and sex; STh and PTh at time 1 were higher than at time 2, while PT increased at the second measurement; and the increase from STh to PT was higher for men than women at both measurement points.

Examination of the source of the interaction was performed on the residuals (40). Differences between the two measurement points for each of the three types of measures were larger for men than women, and this effect was most pronounced in the measurement of PT. In an a posteriori Tukey/B test, the difference between the two measures of PT was significant only for men.

To explore further the differences in the response pattern between men and women, the correlations between the two measurement points were calculated separately for each sex. The following differences were observed.

First, among men, significant negative correlations were found at the first encounter between dental anxiety (DAS1) and sensation and pain thresholds ( $r=-0.40$ for STh1; $r=-0.45$ for PTh1). Among women, the correlations were nonsignificant $(\mathrm{r}=-0.01$ and $\mathrm{r}=-0.09$, respectively). A similar significant pattern was evident for men at the second encounter ( $r=-0.40$ and $r=-0.41$, respectively). Among women, the correlations were nonsignificant $(\mathrm{r}=0.06$ and $\mathrm{r}=-0.16$, respectively).

A second difference is that a significant negative correlation was found among women between PT at the first encounter (PTh1) and subjective evaluation of the experience on a VAS $(r=-0.37)$. Among men, the correlation was positive but nonsignificant $(r=0.18)$. The pattern on the second encounter was similar although nonsignificant ( $\mathrm{r}=-0.14$ for women and $\mathrm{r}=0.08$ for men).

Third, a significant negative correlation was found in women between the MEP and the PTh at the second encounter (PTh2) $(\mathrm{r}=-0.42)$. Among men, the correlation was nonsignificant $(\mathrm{r}=0.05)$.

\section{DISCUSSION}

Pain is a complex sensory and emotional experience that affects, and is affected by, numerous physiological, behavioural, emotional and social factors. Our understanding of this multifactorial phenomenon is far from complete and includes many controversies. One such controversy is the possible differences between sexes concerning PT. Classic notions based on experimental pain research were that men can tolerate more pain than women (41) and that the PT threshold is correlated with the higher anxiety scores in women versus men (8). Such differences have not, however, been found in many of the recent experimental pain research (see 42 for a review).

In the present study no direct relationships were found between sex and the research variables (state and dental anxiety, sensation and PThs, and PT). Furthermore, no significant differences were found between sexes in their subjective evaluations of the painful stimuli on a VAS (PVAS1, MEP and PVAS2).

Recently it was suggested that the differences between sexes regarding reactions to painful pressure stimuli reflect low level sensory and/or affective components of pain rather than attitudinal or response-bias factors (43). Lautenbacher and Rollman (20) showed that different stimulation methods (heat pain, warm and cold thresholds versus electrical detection, pain and tolerance thresholds) produce different results with respect to sex differences in responsiveness to nonpainful and painful stimuli. These researchers assumed that the stimulus characteristics of duration, onset time, etc, determine the amount of stimulus-related anxiety, the level of which may differ between the sexes.

Harris and Rollman (44) showed that threshold judgements, emphasizing discrimination of nociceptive quality, and tolerance decisions, indicating an unwillingness to receive more intense stimuli, are not equivalent measures of responsiveness. Women were shown to have lower values for STh, PTh and PT, but did not differ from men in the growth of sensory magnitude or discriminatory capacity (45). In a laboratory setting, Rollman (46) reported that women terminated an electrical shock at lower self-described pain levels than men. Both sexes came to the laboratory with different PT expectations and anxiety levels. That author concluded that sex differences may be influenced by psychosocial factors, such as expected sex roles.

In the present study the stimulus was electric stimulation of the tooth pulp, a routine, accepted, clinical diagnostic test of pulp vitality. In such a setting dental anxiety was expected to play a significant role in pain perception. Previous studies have shown higher dental anxiety levels among women compared with men $(12,14,25)$, but no such differences were apparent in this study.

The exploratory correlational analyses in the present study did not detect a direct effect of sex and the various pain measures. This finding is in agreement with that of Lander et al (47), who showed that in a clinical (versus a laboratory) setting, women are not differ- 
ent from men in their response to pain. However, this does not necessarily imply that one's sex does not affect the pain experience. It is possible that the relationship among the pain measures affects each sex differently. ANOVA analyses presented here indicate that the increase in PT between the first and second measurements in men was significantly higher than that in women. Thus, men and women may be affected differently by their initial experience. The increase in a man's PT may be due to the higher 'familiarity' of the second encounter, a fact that reduces uncertainty and stress.

Significant differences were also found in the relationship between PT and subjective evaluation of the painful experience by both sexes. There was a negative correlation in women between level of pain tolerated and subsequent evaluation of it on a VAS (an inverse relationship). The correlation among men was positive but not significant.

One possible explanation for the negative correlation is that women agreed to tolerate higher pain levels because they actually experienced less pain. If this is true there should be differences in the pain threshold measures between sexes. In our study, however, no significant differences were found in the pain measures (STh, PTh, PT) between men and women at the two measurement points (no correlation between sex and any of those variables). It may therefore be possible that pain evaluation is determined differently by each sex. Women may be affected more by the objective characteristics of the stimulus, whereas men may also be more affected by other variables (eg, psychological factors).

This notion is further buttressed in that the sensation and pain thresholds of men were more affected by their level of dental anxiety than were women. In addition, in women, the lower their pain memory, the higher their PTh at the second measurement, and vice versa. For men, these correlations were not significant.

That the expression of fear by men is affected by their conforming to the traditional male sex role - causing them to 'lie' on fear surveys - has been discussed (48). In a comprehensive review on sex and clinical pain experience, Unruh (42) summarized that men may be more embarrassed by pain than women, and that the mean-

ACKNOWLEDGEMENTS: The authors thank Ms Rita Lazar for editorial assistance.

\section{REFERENCES}

1. McNeil DW, Berryman ML. Components of dental fear in adults? Behav Res Ther 1989;27:233-6.

2. Dangott L, Thornton BC, Page P. Communication and pain. J Commun 1978;28:30-5.

3. Klepac RK, Dowling J, Hauge G, McDonald M. Reports of pain after dental treatment, electrical tooth pulp stimulation and cutaneous shock. J Am Dent Assoc 1980;100:692-5.

4. Craig KD. Emotional Aspects of Pain. In: Wall PD, Melzack RA, eds. Textbook of Pain, 2nd edn. London: Churchill Livingston, 1989.

5. Weisenberg M. Pain and pain control. Psychol Bull 1977;84:1008-44.

6. Von Graffenried B, Adler R, Abt K, Nuesch E, Spiegel R. The influence of anxiety and pain sensitivity on experimental pain in man. Pain 1978;4:253-63.

7. Sternbach RA. Clinical Aspects of Pain. In: Sternbach RA, ed. The Psychology of Pain, 2nd edn. New York: Raven Press, 1978.

8. Robin O, Vinard H, Vernet-Maury E, Saumet JT. Influence of sex and anxiety on pain threshold and tolerance. Funct Neurol 1987;2:173-9.

9. Bowers KS. Pain, anxiety, and perceived control. J Consult Clin Psychol 1968;32:596-602.

10. Klepac RK, McDonald M, Hauge G, Dowling J. Reactions to pain ing of pain may be affected by sociocultural factors and the perceived position of men and women in society. Our data suggest that not only the report of anxiety, but also the pain experience are affected differently by psychological factors in both sexes.

Bush and co-workers (19) assessed the effect of sex on chronic pain perception and symptom presentation in temporomandibular pain. Several sex differences concerning the ratings of chronic or experimental pain, pain-related illness behaviour and personality were found. Their results regarding experimental pain lend credence to the view of different factors determining responses to experimental pain among sexes. Levine and De Simone (49) showed that men report significantly less pain in front of a female experimenter than a male experimenter, whereas women are not affected by such a factor. This supports our interpretation and indicates that the pain experience in men is possibly more affected by psychological factors compared with women.

\section{CONCLUSIONS}

The present study included three pain threshold measures (STh, PTh and PT) together with evaluative measures relating to pain (PVAS1, MEP, PVAS2). Pain threshold measures were highly correlated among themselves but were not correlated with any of the evaluative measures of pain (the latter correlating only among themselves). This is in agreement with findings from Harris and Rollman (44), who showed that threshold and tolerance measures, while related, do not tap identical components of the pain experience. It is likely that we are dealing with two distinct measures of the pain experience; one (pain threshold measures) that is less affected by anxiety and one (evaluative measures of pain) that is more affected. This confirms results obtained in a previous study (50) and calls for further research.

While intriguing, the correlations presented in this study are exploratory and should be considered as a basis for future research. One suggestion is that women and men make somewhat different assessments of the pain experience.

among subjects high and low in dental fear. J Behav Med 1980;3:373-84.

11. Kent G. Anxiety, pain and type of dental procedure. Behav Res Ther 1984;22:465-9.

12. Green RM, Green A. Adult attitudes to dentistry among dental attenders in South Wales. Br Dent J 1985;159:157-60.

13. Kent G. Memory of dental pain. Pain 1985;21:187-94.

14. Klepac RK, Dowling J, Hauge G. Characteristics of clients seeking therapy for the reduction of dental avoidance: Reactions to pain. J Behav Ther Exp Psychiatry 1982;13:293-300.

15. Anderson DB, Pennebaker JW. Pain and pleasure: Alternative interpretations for identical stimulation. Eur J Soc Psychol 1980;10:207-12.

16. Dworkin SF, Chen AC. Pain in clinical and laboratory contexts. J Dent Res 1982;61:772-4.

17. Kent G. Memory of dental experiences as related to naturally occurring changes in state anxiety. Cognit Emotion 1989;3:45-53.

18. Ruda MA. Gender and pain. Pain 1993;53:1-2.

19. Bush FM, Harkins SW, Harrington WG, Price DD. Analysis of gender effects on pain perception and symptom presentation in temporo-mandibular pain. Pain 1993;53:73-80.

20. Lautenbacher S, Rollman GB. Sex differences in responsiveness to painful and non-painful stimuli are dependent upon the stimulation method. Pain 1993;53:255-64.

21. Rowe AHR, Pitt Ford TR. The assessment of pulpal vitality. Int Endod J 1990;23:77-83. 
22. Eli I. Psychophysiology: Stress, Pain and Behavior in Dental Care. Boca Raton: CRC Press, 1992.

23. Milgrom P, Fiset L, Melnick S, Weinstein P. The prevalence and practice management consequences of dental fear in a major US city. J Am Dent Assoc 1988;116:641-7.

24. Domoto PK, Weinstein P, Melnick S, et al. Results of a dental fear survey in Japan: Implications for dental public health in Asia. Community Dent Oral Epidemiol 1988;16:199-201.

25. Eli I. Dental anxiety: A cause for possible misdiagnosis of tooth vitality. Int Endod J 1993;26:251-3.

26. Spielberger CD, Gorsuch R, Lushene R. The State Trait Anxiety Inventory (STAI). Riverside: Consulting Psychologists Press, 1970.

27. Corah NL. Development of a dental anxiety scale. J Dent Res 1969;48:596.

28. Corah NL, Gale EN, Illig SJ. Assessment of a dental anxiety scale. J Am Dent Assoc 1978;97:816-9.

29. Berggren U, Carlsson SG. Psychometric measures of dental fear. Community Dent Oral Epidemiol 1984a;12:319-24.

30. Berggren U, Carlsson SG. A psychophysiological therapy for dental fear. Behav Res Ther 1984b;22:487-92.

31. Berggren U, Carlsson SG. Usefulness of two psychometric scales in Swedish patients with severe dental fear. Community Dent Oral Epidemiol 1985;13:70-4.

32. Berggren U, Carlsson SG. Qualitative and quantitative effects of treatment for dental fear and avoidance. Anesth Prog 1986;33:9-13.

33. Berggren U, Linde A. Dental fear and avoidance: A comparison of two modes of treatment. J Dent Res 1984;63;1223-7.

34. Berggren U, Meynert G. Dental fear and avoidance: Causes, symptoms, and consequences. J Am Dent Assoc 1984;109:247-51.

35. Berggren U. Long-term effects of two different treatments for dental fear and avoidance. J Dent Res 1986;65:874-6.

36. Carlsson SG, Linde A, Berggren U, Harrison JA. Reduction of dental fear: Psychophysiological correlates. Community Dent Oral Epidemiol 1986;14:253-7.

37. Frazer M, Hampson S. Some personality factors related to dental anxiety and fear of pain. Br Dent J 1988;165:436-9.

38. Kunzelmann K-H, Dunninger P. Dental fear and pain: Effect on patient's perception of the dentist. Community Dent Oral Epidemiol 1990;18:264-6.

39. Locker D, Liddell AM. Correlates of dental anxiety among older adults. J Dent Res 1991;70:198-203.

40. Rosnow RL, Rosenthal R. Definition and interpretation of interaction effects. Psychol Bull 1989;105:143-6.

41. Woodrow KM, Friedman GD, Siegelaub AB, Collen MF. Pain tolerance: Differences according to age, sex and race. Psychosom Med 1972;34:548-56

42. Unruh AM. Gender variations in clinical pain experience. Pain 1996;65:123-67.

43. Ellermeier W, Westphal W. Gender differences in pain ratings and pupil reactions to painful pressure stimuli. Pain 1995;61:435-9.

44. Harris G, Rollman GB. The validity of experimental pain measures. Pain 1983;17:369-76.

45. Rollman GB, Harris G. The detectability, discriminability, and perceived magnitude of painful electrical shock. Percept Psychophys 1987;42:257-68.

46. Rollman GB. Gender differences in pain. Pain Forum 1995;4:231-4.

47. Lander J, Fowler-Kerry S, Hill A. Comparison of pain perceptions among males and females. Can J Nurs Res 1990;22:39-49.

48. Pierce KA, Kirkpatrick DR. Do men lie on fear surveys? Behav Res Ther 1992;30:415-8.

49. Levine FM, De Simone LL. The effects of experimenter gender on pain report in male and female subjects. Pain 1991;44:69-72.

50. Eli I, Bar-Tal Y, Fuss Z, Silberg A. Effect of intended treatment on anxiety and on electric pulp stimulation in dental patients. J Endo. (In press) 


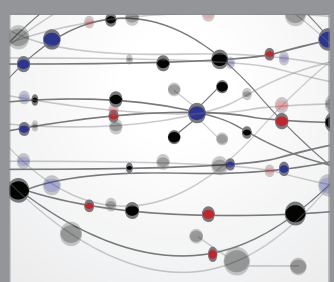

The Scientific World Journal
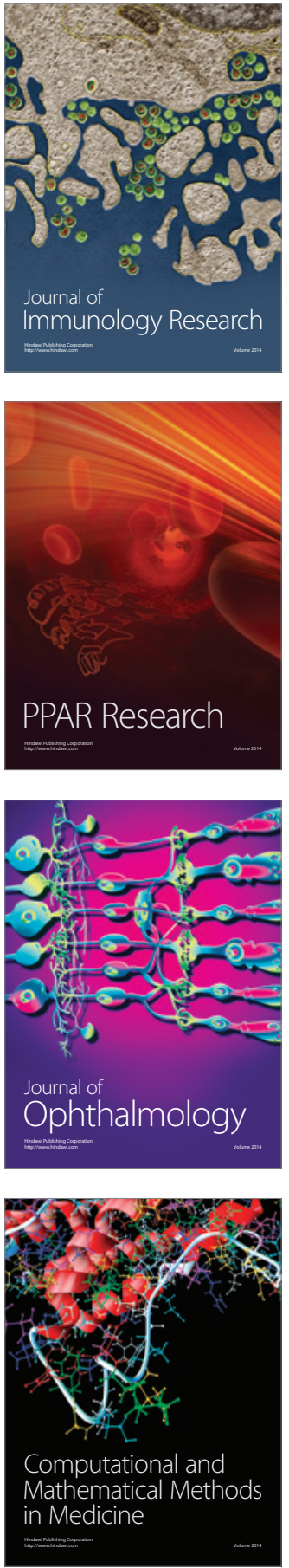

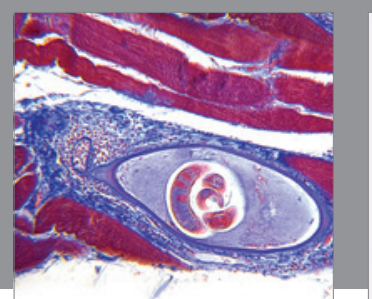

Gastroenterology Research and Practice

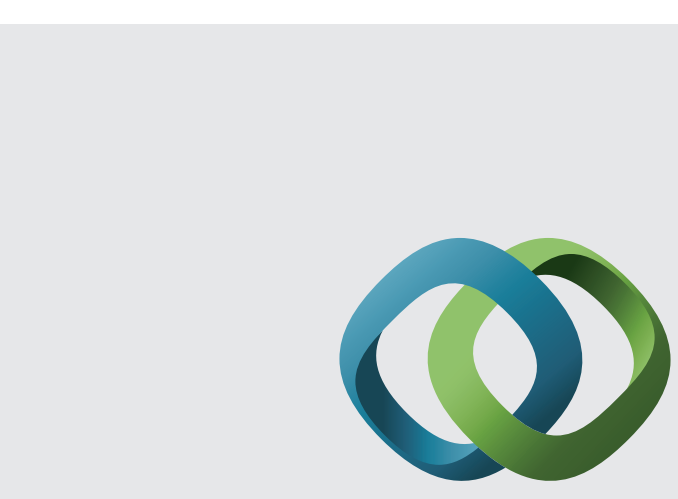

\section{Hindawi}

Submit your manuscripts at

http://www.hindawi.com
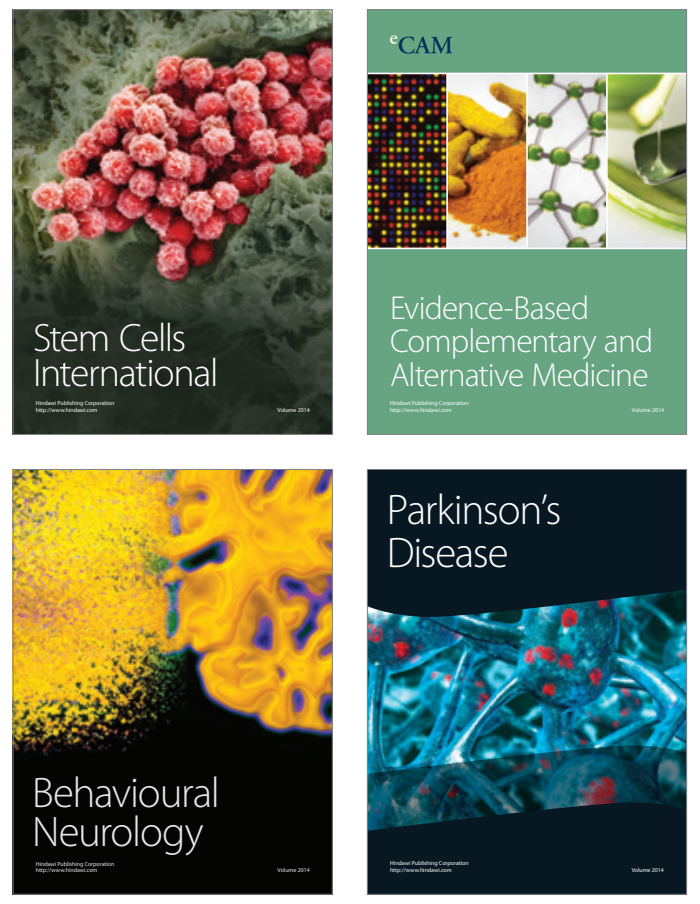
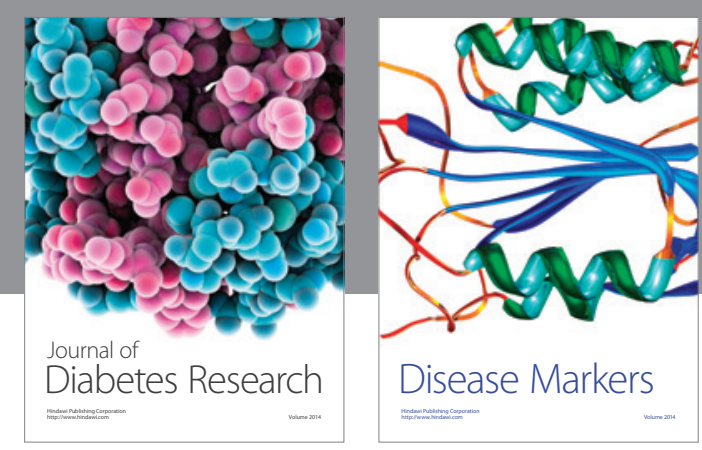

Disease Markers
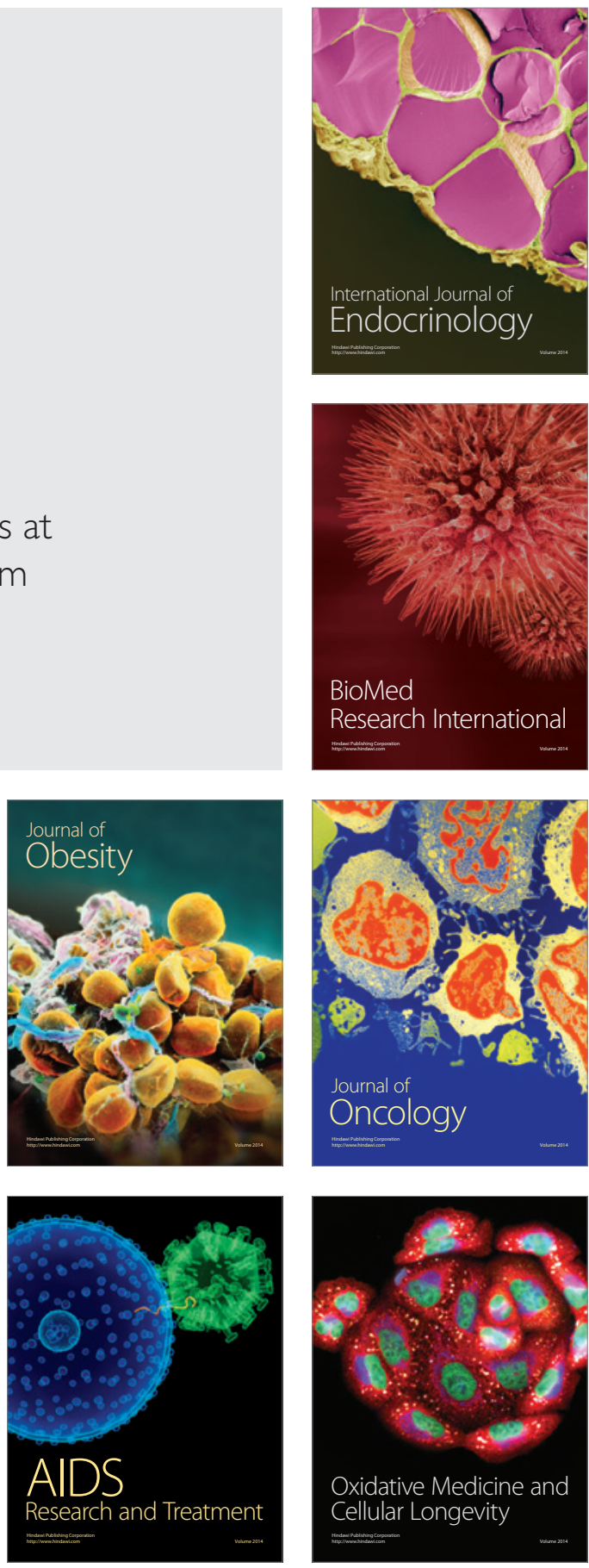